\title{
MENINGKATKAN CITRA UKM \\ MELALUI PERANCANGAN ULANG IDENTITAS VISUAL
}

\author{
Lintang Widyokusumo \\ Visual Communication Design, School of Design, BINUS University \\ Jln. K.H. Syahdan No. 9, Palmerah, Jakarta Barat 11480 \\ lintangw@binus.edu
}

\begin{abstract}
The shift of economic trend into creative economy spurs Indonesia as a creative nation supported with cultural diversity, creative human resources and rich of natural resources to actively participate and contribute to the global economy. The power of Indonesian's creative products is not inferior to other countries. However, the appeal of a product cannot be separated from the role of consistent and good visual identity design. Through this program Indonesian's creative products will be more dignified, classy and echoed throughout the world.
\end{abstract}

Keywords: creative industry, visual identity program, creative product

\begin{abstract}
ABSTRAK
Beralihnya tren ekonomi menjadi ekonomi kreatif memacu Indonesia sebagai bangsa yang kreatif dengan didukung keragaman budaya, sumber daya manusia kreatif, dan sumber daya alam yang melimpah untuk turut aktif dan berperan dalam ekonomi global. Kekuatan produk-produk kreatif Indonesia tidak kalah dengan negara-negara maju lainnya. Meskipun demikian, daya tarik suatu produk tidak bisa lepas dari peran perancangan suatu program identitas visual yang baik dan menerus. Melalui program ini produk-produk kreatif dalam negeri akan lebih bermartabat, berkelas, dan terdengar di dunia.
\end{abstract}

Kata kunci: industri kreatif, program identitas visual, produk kreatif 


\section{PENDAHULUAN}

Di Indonesia harapan untuk membangkitkan ekonomi rakyat sering didengar. Hal itu disebabkan pengalaman saat krisis multidimensi tahun 1997-1998 usaha kecil telah terbukti mampu mempertahankan kelangsungan usahanya. Bahkan, mereka memainkan fungsi penyelamatan di beberapa subsektor kegiatan. Bukti tersebut paling tidak telah menumbuhkan optimisme baru bagi sebagian besar orang yang menguasai sebagian kecil sumber daya terhadap kemampuannya untuk menjadi motor pertumbuhan bagi pemulihan ekonomi.

Harapan ini menjadi makin kuat ketika muncul keberanian untuk mempercepat pemulihan dengan motor pertumbuhan Usaha Kecil Menengah (UKM). Semangat baru dunia yang menggeluti usaha kecil dan menengah juga telah berketetapan hati untuk menjadikan UKM sebagai motor pertumbuhan ekonomi di masa depan. Pernyataan ini paling tidak telah menjadi kesadaran baru bagi kalangan pelaku UKM di kawasan Asia Pasifik sebagai mana dikemukakan di depan para menteri yang membidangi UKM forum APEC yang bertemu di kota Christchurch New Zealand tahun 1999. Pengalaman, keyakinan, dan harapan ini yang kemudian menggelora menjadi semangat yang terus didengungkan hingga saat ini (Depdag RI, 2009).

Permasalahan yang tidak kalah pentingnya dalam mata rantai pemasaran, di samping terkait dengan banyaknya pesaing yang bergerak dalam industri yang sama, adalah juga akibat relatif minimnya penetrasi pasar di luar negeri dalam hal ini masalah tampilan visual label ataupun kemasan produk itu sendiri yang kurang representatif. Di dalam label ataupun kemasan terdapat logo merek ataupun informasi-informasi penting yang perlu diketahui oleh konsumen dan seharusnya digarap apik, indah, dan professional. Desain label atau kemasan tidak harus dengan material yang mahal. Kreativitas ekstra bagi seorang desainer grafis dibutuhkan untuk menghasilkan desain yang inovatif dan menarik namun rendah budget. Hal tersebut penting karena para pelaku UKM tidak menginginkan ongkos produksi yang tinggi dan berimbas pada harga jual yang makin membengkak.

\section{Potensi Produk Kreatif Indonesia}

UNESCO pada 2003 mengeluarkan rilis resmi mengenai definisi industri kreatif sebagai suatu kegiatan yang menciptakan pengetahuan, produk, dan jasa yang orisinal, berupa hasil karya sendiri. Kontribusi industri kreatif di Indonesia terhadap PDB ini terbilang lebih rendah dibandingkan kontribusi industri kreatif di negara maju, seperti Inggris yang industri kreatifnya mampu berkontribusi sebesar 9\% terhadap PDB (Depdag RI, 2009). Namun dukungan pemerintah cukup baik dengan mengidentifikasikan lingkup industri kreatif mencakup 14 subsektor, antara lain industri software, pasar barang seni, industri kerajinan, fashion, periklanan, desain animasi, film, video dan fotografi, musik serta permainan interaktif. Di sinilah peran serta industry kreatif untuk bergandengan tangan dalam mengemas UKM agar dapat lebih berbicara di dunia internasional dengan tampilan yang lebih profesional dan meyakinkan importir.

\section{Merek Lokal Membutuhkan Identitas Visual}

UKM adalah merek lokal yang menjadi ujung tombak devisa negara mempunyai kebutuhan akan program identitas visual. Merek lokal harus mampu bersaing dengan merek yang ditawarkan oleh negara lain sebagai kompetitor di pasar global. "A logo is the point of entry to the Brand," begitu menurut Milton Glaser, seorang desainer. Lalu mengenai waktu produk kreatif dalam negeri membutuhkan sebuah program perancangan identitas visual, berikut adalah ini beberapa alasan sebuah organisasi atau unit usaha membutuhkan suatu program identitas visual baru. Pertama, unit usaha baru dengan produk baru; kedua, melakukan perubahan nama; ketiga, membangun citra baru; keempat, mengubah identitas visual (logo) lama; kelima, menciptakan sistem; keenam, memperluas usaha (merging company). (Wheeler, 2013) 


\section{Perbedaan Citra, Identitas, dan Logo}

Logo adalah sebuah gambar grafis yang dapat merepresentasikan sebuah citra. Citra yang terbentuk dari pengalaman-pengalaman konsumen dan membentuk sebuah persepsi di dalam benak mereka terhadap sebuah produk, organisasi atau perusahaan. Identitas tidak semata hanya terwakili oleh sebuah logo namun lebih luas dari itu. Identitas mencakup elemen aplikasi dari sebuah logo yang terintegrasi dalam skema warna, kop surat, kartu nama, amplop, website atau bahkan interior dari toko maupun kantor dari organisasi tersebut.

Namun identitas tanpa sebuah logo adalah seperti sebuah kereta api yang berjalan tanpa kota pemberhentian akhir. Konsumen akan bingung siapakah pemilik identitas semua ini. Sebuah Usaha Kecil Menengah (UKM) dalam berkompetisi di era industri kreatif ini layak untuk berinvestasi pada sebuah program identitas visual. Beberapa manfaat dari program tersebut adalah sebagai berikut.

Pertama, memudahkan konsumen untuk membeli produk. Program identitas visual dapat memudahkan konsumen untuk membeli produk di website (luar kota, luar pulau, bahkan luar negeri). Lebih lanjut, identitas visual dapat membantu untuk membedakan persepsi sebuah produk dengan kompetitor yang lain. Kedua, memudahkan penjualan produk. Dengan program identitas visual organisasi dapat menembus ke berbagai ragam konsumen dan budaya untuk membangun kesadaran dan memahami produk/organisasi dan kekuatan serta kelebihannya. Tentunya melalui pemilihan media iklan yang tepat, kartu nama bahkan template untuk presentasi produk. Ketiga, memudahkan membangun citra sebuah produk. Jika sebuah produk sudah mempunyai reputasi yang baik atau bahkan belum sampai ke taraf tersebut, program identitas visual dapat membantu membangun citra dengan meningkatkan pengenalan dan kampanye tentang produk atau organisasi dalam membangun loyalitas konsumen (Wheeler, 2013).

\section{METODE}

Artikel disusun berdasarkan studi pustaka, yaitu menyeleksi beberapa sumber referensi baik cetak maupun elektronik dan observasi pada beberapa UKM di lingkungan kampus. Kemudian, informasi tersebut dirangkum menjadi dasar penulisan artikel ini.

\section{HASIL DAN PEMBAHASAN}

Tahapan sederhana dalam proses menuju identitas dengan contoh kasus UKM sekitar kampus Binus adalah riset dan analisis, strategi pencitraan, konsep desain, dan pengembangan pencitraan. Dalam tahapan riset dan analisis penelitian mendefinisikan visi, goal dan value, riset terhadap persepsi dan kebutuhan konsumen, evaluasi pencitraan saat ini dan pengembangannya. Objek penelitian adalah UKM di lingkungan kampus (Gambar 1) yang berusaha untuk bertahan di era industri kreatif. Untuk langkah awal program perancangan ulang identitas visual, riset lapangan melalui interview merupakan langkah awal untuk menggali informasi seperti visi dan misi organisasi tersebut, logo dan item promosi saat ini, dll. 




Gambar 1 Beberapa UKM yang berada di sekitar jalan Syahdan (Dokumentasi Penulis)

Pada tahap strategi pencitraan penelitian membangun positioning (keunggulan produk terhadap kompetitor), penciptaan nama, dan pencitraan baru. Sedangkan konsep desain memberi gambaran kasar tentang pengembangan visual ke depan, mendesain identitas visual, pengembangan identitas visual, dan strategi visual. Selanjutnya tahap pengembangan pencitraan merupakan tahapan akhir untuk memberi solusi desain, membuat panduan pengembangan identitas, dan pencitraan.

Gambar 2 adalah sebagian contoh dari karya mahasiswa Binus. Gambar tersebut memperlihatkan desain buku panduan grafis untuk petunjuk teknis aplikasi logo sebuah toko kudapan tradisional "Cemal-Cemil".



Gambar 2 Contoh Layout Buku Petunjuk Aplikasi Logo Toko “Cemal-Cemil” (Karya Mahasiswa DKV Binus) 
Berbagai esensi harus diperhatikan dalam perancangan sebuah logo sebagai identitas visual. Contoh eksekusi logo pada gambar-gambar selanjutnya adalah karya dari mahasiswa DKV Binus semester 5 dengan contoh kasus UKM yang ada di sekitar lingkungan kampus. Uraian isi eksekusi terangkum sebagai berikut.

Pertama, logo ilustrasi secara gamblang mengilustrasikan sebuah produk atau servis; atau bahkan beberapa menyiratkan sebuah simbol (Budelmann, 2010). Keuntungan logo ilustrasi adalah kemudahan bagi konsumen untuk memahami produk atau jasa yang ditawarkan. Dua karya berikut (Gambar 3 dan 4) adalah contoh logo ilustrasi yang menggambarkan secara langsung jenis produk/jasa yang ditawarkan pada konsumen, yaitu Malda (penjahit jeans yang sekaligus menjual kain bahannya) dan "Karya Pribumi” (toko material bahan bangunan).
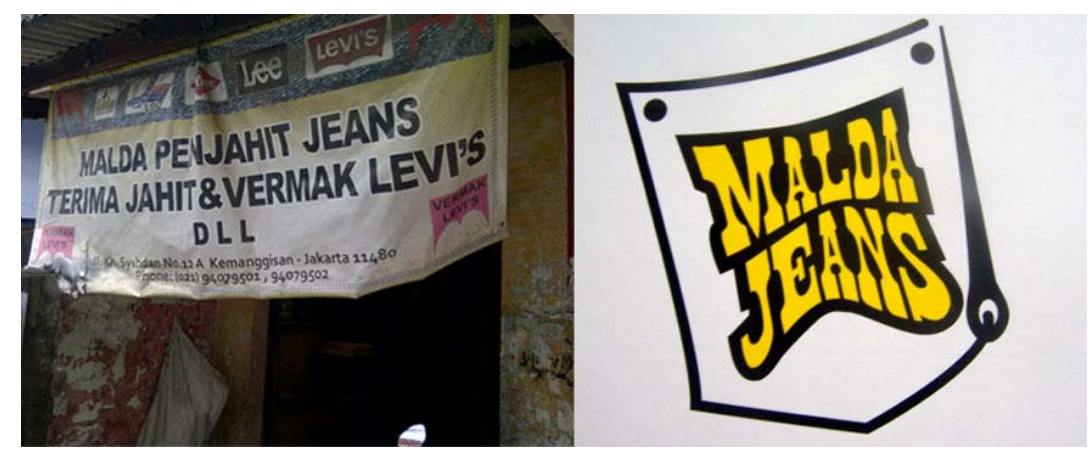

Gambar 3 Sebelum dan Sesudah Desain Ulang Logo Malda Jeans (Karya Mahasiswa DKV Binus)

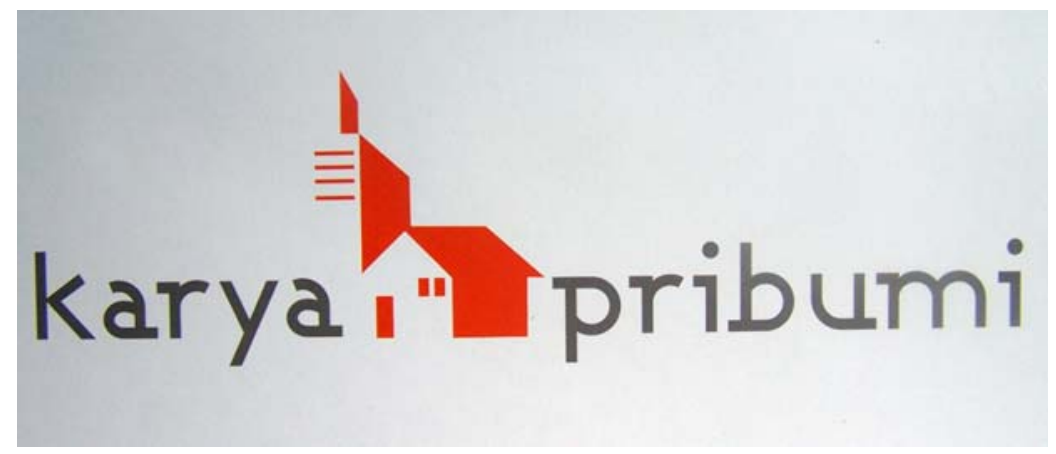

Gambar 4 Logo Karya Pribumi (Karya Mahasiswa DKV Binus)

Kedua, pemilihan warna. Warna memberikan sentuhan emosional kepada logo. Namun perlu diperhatikan pula limitasi kebutuhan warna pada logo berhubungan dengan proses produksi (maksimum 3 warna). Terkadang pilihan warna banyak dipengaruhi oleh tren karena warna pun mempunyai masa kedaluwarsa. Tidak heran jika program perancangan ulang identitas visual akan berulang pada masa mendatang sesuai dengan kebutuhan dan tren produk/jasa tersebut. Selain tren, pemilihan warna juga berdasarkan konsep desainer untuk mempersepsikan produk/jasa kepada konsumen. Gambar 5 merupakan sebuah toko refill tinta printer. Pada pemilihan warna pada logo simbol diperlihatkan beberapa warna dasar yang ada pada tinta. Keragaman warna juga menunjukkan optimistis dalam bisnis (pengembangan bisnis) dan keragaman pilihan warna dan jenis tinta. 




Gambar 5 Sebelum dan Sesudah Desain Ulang Logo Veneta System (Karya Mahasiswa DKV Binus)

Ketiga, kontras dalam komposisi. Kontras dalam peletakan maupun ukuran membuat sebuah logo tampak berbeda dengan lainnya. Kontras juga memperlihatkan penekanan mana dari logo tersebut yang menjadi perhatian atau yang dikomunikasikan. Gambar logo berikut adalah perancangan ulang identitas visual/logo dari kios duplikat kunci. Desainer ingin memberikan penekanan pada kata "Raje" agar terbaca jelas sebagai merek (memberikan jenis huruf Bold) dibanding kata "Kunci" yang berfungsi sebagai kata keterangan jenis usaha yang ditawarkan dengan jenis huruf light. Pemilihan jenis huruf Sans Serif mewakili kesan modern dan servis yang cepat. Selain itu komposisi menarik antara simbol kunci dengan logotype.

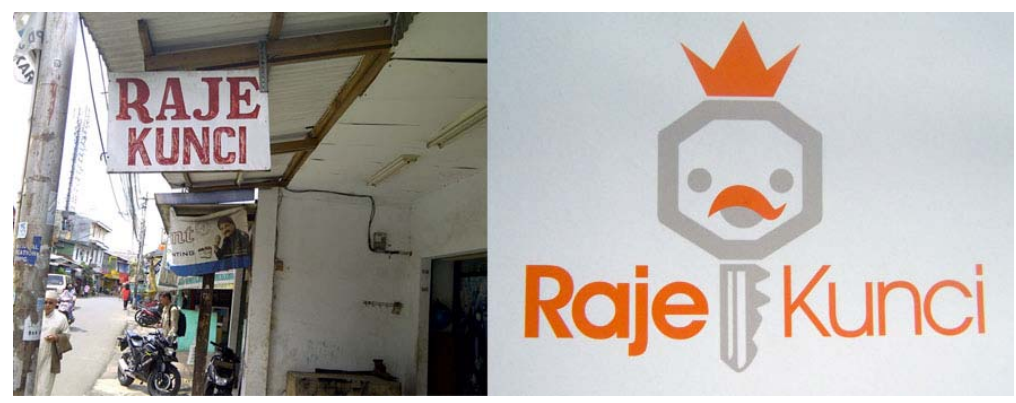

Gambar 6 Sebelum dan Sesudah Desain Ulang Logo Raje Kunci (Karya Mahasiswa DKV Binus)

Keempat, keunikan bentuk logo. Keunikan suatu bentuk logo turut menyumbang perhatian lebih konsumen disbanding competitor lainnya. Bentuk terkadang menciptakan memori tersendiri dalam benak konsumen: apakah bulat, simetris, asimetris, tebal, tipis, kotak, bentuk bebas. Gambar 7 memperlihatkan sebuah logo warnet yang menawarkan bermacam game (PS2). Desainer mencoba memberikan sentuhan Manga pada symbol logo tersebut dengan memanfaatkan elemen sebuah topeng samurai. Bentuk bebas dipilih namun tetap simetris.

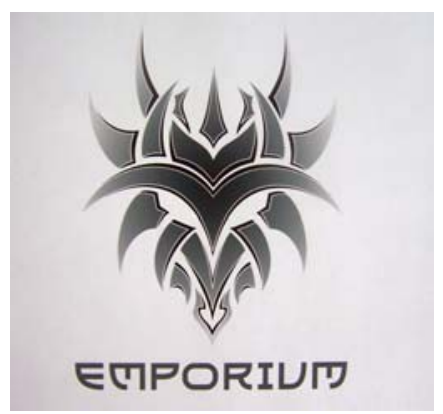

Gambar 7 Desain Ulang Logo Emporium (Karya Mahasiswa DKV Binus) 
Keempat, monogram dan logotype. Inisial dan logotype/word marks adalah pilihan bentuk logo yang menggunakan inisial huruf ataupun sederet huruf yang menbentuk satu kata atau lebih. Terkadang bentuk inisial atau logotype dimodifikasi untuk disesuaikan dengan kebutuhan informasi yang diperlukan oleh konsumen untuk mengetahui jenis produk/jasa yang ditawarkan. Dua gambar berikut (Gambar 8 dan 9) menjelaskan dua logo yang menggunakan inisial "S" untuk warung makan "Surabaya" dan inisial "SG" untuk restoran "Sola Gratia". Inisial huruf tidak hanya diambil apa adanya dari keluarga huruf namun diolah kembali dan disesuaikan dengan kebutuhan produk/jasa yang ditawarkan.

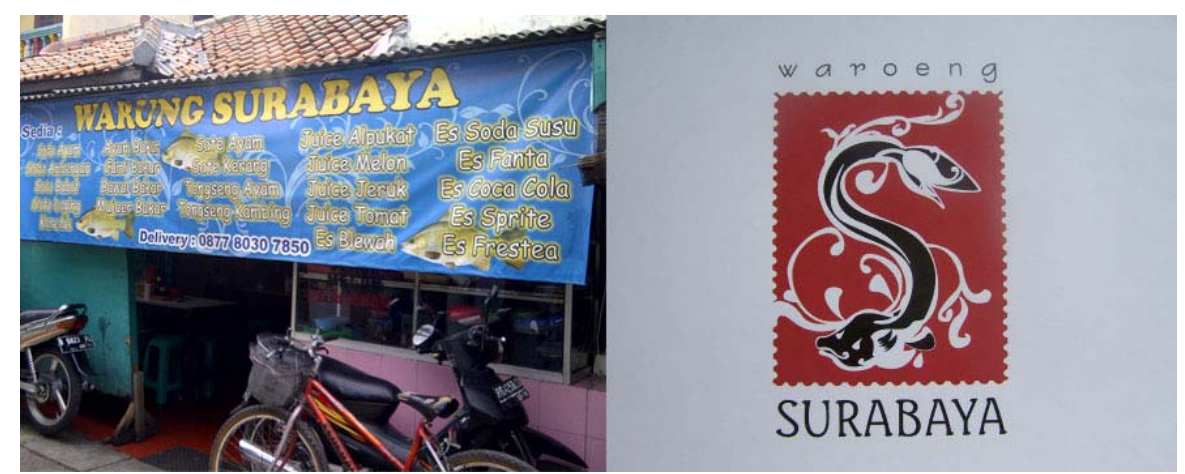

Gambar 8 Sebelum dan Sesudah Desain Ulang Logo Warung Surabaya (Karya Mahasiswa DKV Binus)

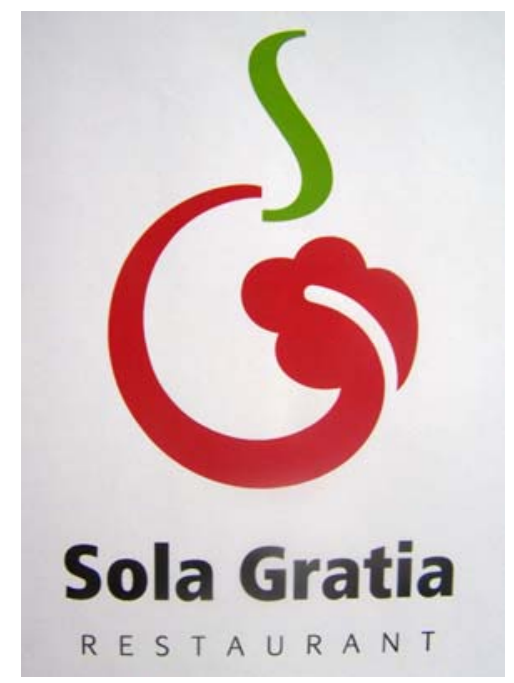

Gambar 9 Desain Ulang Logo Restoran Sola Gratia (Karya Mahasiswa DKV Binus)

Kelima, jenis huruf yang sesuai. Huruf mempunyai personalitas. Pilihan jenis huruf yang tepat memberikan rasa yang selaras dengan personalitas produk/jasa/organisasi. Sebagai contoh, sign system selalu menggunakan jenis huruf Sans Serif (tidak berkait) karena Sans Serif selalu diasosiasikan modern, sederhana, dan lugas. Jenis huruf Serif (berkait) selalu dirasakan klasik dan kuno namun kuat. Dua contoh logo berikut adalah contoh logotype yang menggunakan jenis huruf dekoratif. Jenis huruf yang dipilih disesuaikan dengan jenis jasa/produk yang kontemporer, riang, sehat, ringan, dan harga terjangkau. 


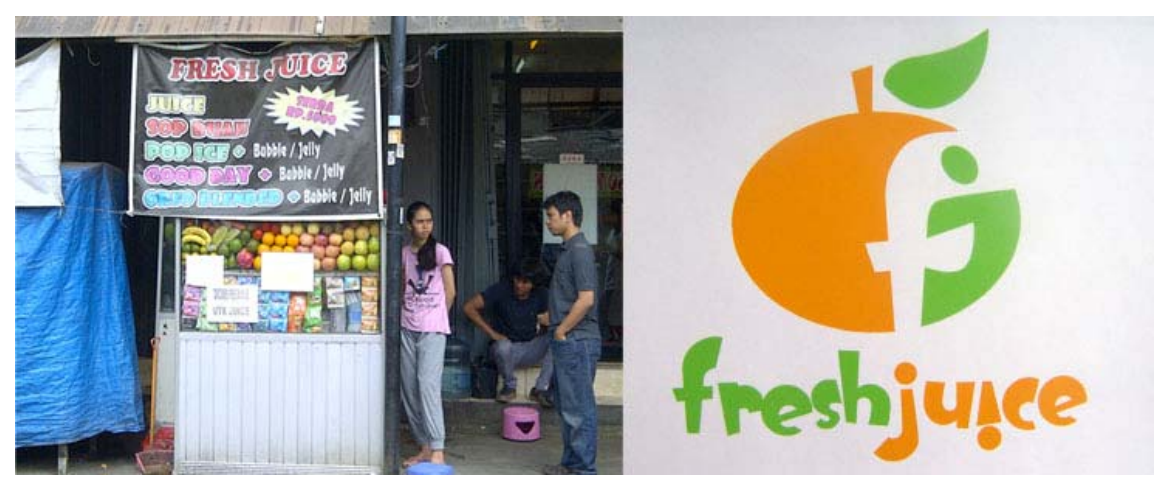

Gambar 10 Sebelum dan Sesudah Desain Ulang Logo Fresh Juice

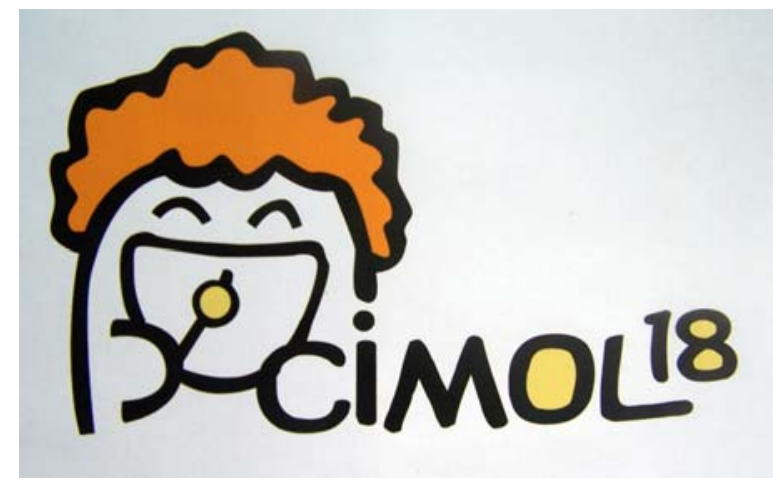

Gambar 11 Desain Ulang Logo Cimol 18 (Karya Mahasiswa DKV Binus)

Keenam, tagline yang menjual. Sebuah logo terkadang tidak hanya sekadar menampilkan logo seorang diri tetapi juga menambahkan kata pelengkap keterangan untuk menguatkan positioning dan identitas mereka (tagline). Dua contoh gambar berikut adalah contoh sebuah logo dipadukan dengan tagline sebagai keterangan bisnis yang dijalankan dan positioning yang dikomunikasikan.

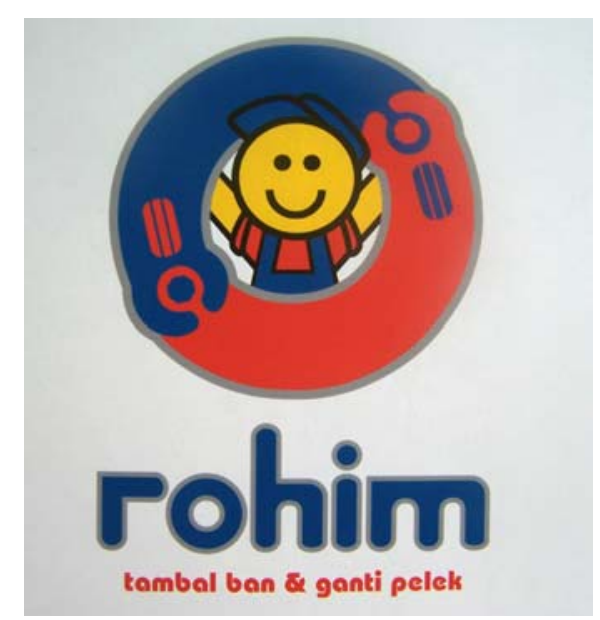

Gambar 12 Desain Ulang Logo Rohim (Karya Mahasiswa DKV Binus) 


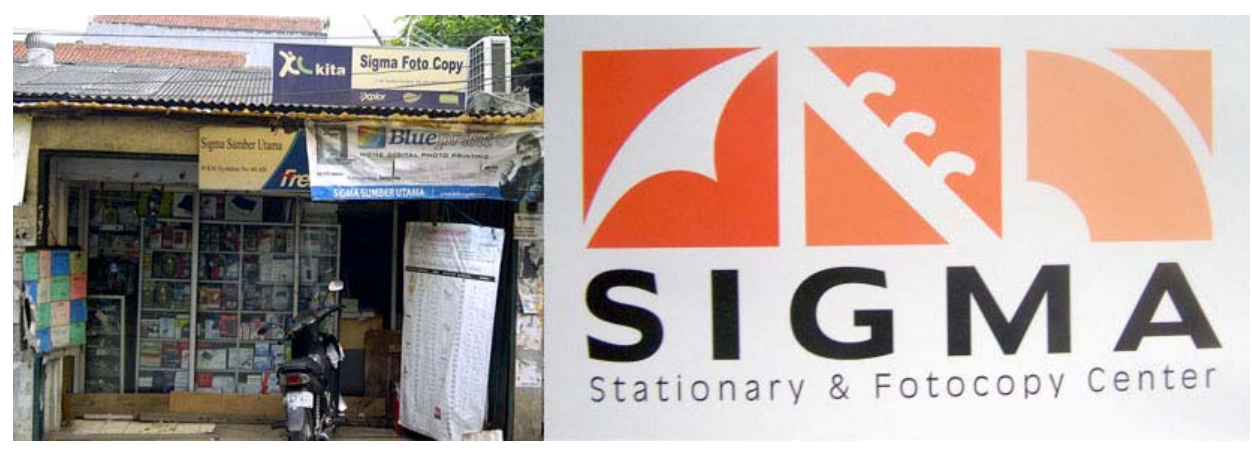

Gambar 13 Sebelum dan Sesudah Desain Ulang Logo Sigma

(Karya Mahasiswa DKV Binus)

\section{SIMPULAN}

Era ekonomi kreatif memacu industri kreatif dalam negeri untuk dapat lebih bersaing dengan produk-produk luar yang mulai merangsek masuk dalam putaran perekonomian. Peluang ekspor pun dapat disikapi sebagai peluang bisnis yang mampu mendatangkan devisa yang tidak sedikit. Nilai ekspor industri kreatif berkontribusi sebesar sekitar 90 persen terhadap total nilai ekspor nasional dengan penyerapan tenaga kerja mencapai 5,4 juta pekerja (Depdag RI 2009).

Potensi dan peluang tersebut tidak boleh disia-siakan. Pengenalan sebuah produk/jasa membutuhkan program perancangan identitas yang baik dan menerus. Saat ini komunikasi pencitraan sebuah produk/jasa/organisasi tidak hanya dilakukan melalui media konvensional tetapi juga merambah dunia maya melalui media sosial. Semua orang harus yakin dan mampu mengantisipasi untuk menghadapi semua tantangan global ini.

\section{DAFTAR PUSTAKA}

Budelmann, K. (2010). Brand Identity Essentials. Singapore: Page One.

Departemen Perdagangan Republik Indonesia. (2009). Presentasi Departemen Perdagangan Republik Indonesia.

Wheeler, A. (2013). Designing Brand Identity. New Jersey: John Wiley \& Sons. 